Article

\title{
High-Temperature Permittivity and Microwave Pretreatment Characteristics of Nickel-Containing Sludge from Battery Production
}

\author{
Zhanyong Guo ${ }^{1}$, Ping Guo ${ }^{2}$, Guang Su ${ }^{1, *}$, Demei Zhai ${ }^{1}$, Fang Cheng ${ }^{1}$ and Fachuang Li ${ }^{1, *}$ \\ 1 School of Materials Science and Engineering, Henan Institute of Technology, Xinxiang 453003, China; \\ guozhanyong123@126.com (Z.G.); zhaidemei@163.com (D.Z.); yay901216@yeah.net (F.C.) \\ 2 Yunnan Provincial Key Laboratory of Intensification Metallurgy, Kunming 650093, China; gp1230@126.com \\ * Correspondence: 13781909400@hait.edu.cn (G.S.); cwd818@163.com (F.L.); Tel.: +86-0373-3691137 (G.S.)
}

Received: 20 March 2019; Accepted: 28 April 2019; Published: 3 May 2019

\begin{abstract}
Permittivity is a vitally important parameter for the description of the absorption and heating characteristics of materials under microwave irradiation. In this paper, the permittivity of nickel-containing sludge (NCS), which is created during battery production as a cheap secondary resource, was measured at temperatures from $20^{\circ} \mathrm{C}$ to $600^{\circ} \mathrm{C}$ at $2.45 \mathrm{GHz}$ using the cavity perturbation method. In addition, the loss tangent $(\tan \delta)$ and penetration depth $(D p)$ of microwaves into the material were calculated. The results of the permittivity study show that the dielectric constant $\left(\varepsilon^{\prime}\right)$ and dielectric loss factor $\left(\varepsilon^{\prime \prime}\right)$ of the NCS increase with increasing temperature. The variations of the loss tangent $(\tan \delta)$ and penetration depth $(D p)$ with the temperature can be divided into two parts at $200{ }^{\circ} \mathrm{C}$. The effect of the initial moisture content on the dielectric properties of the material is notably greater than that of the temperature, which was confirmed by the heating curve. After microwave pretreatment, the nickel-containing phase is transformed into $\mathrm{NiO}$, while the weight of NCS is reduced by more than $20 \%$, the particle size is significantly reduced and the leaching time reduce 20 min than that of conventional heating.
\end{abstract}

Keywords: nickel-containing sludge; microwave; dielectric properties

\section{Introduction}

Nickel-containing sludge (NCS) is a type of nocuous solid waste including $\mathrm{Ni}, \mathrm{Cd}, \mathrm{Fe}, \mathrm{Cu}, \mathrm{Ca}$, and other main components that formed by chemical precipitation of nickel-containing wastewater produced during nickel plating [1,2]. If not handled properly, secondary pollution will occur, which will have a huge impact on the ecological environment and human health. At the same time, NCS contains valuable metals, which can be used as cheap secondary resources containing nickel. Currently, commonly used treatment methods include the separation and recovery of heavy metals $[3,4]$ and stabilization treatment $[5,6]$. However, the composition of NCS is extremely complex. In addition to containing a lot of water, it also contains a lot of ash, inorganic particles, colloids, and other harmful substances [7]. If ammonium leaching [8] or sulfuric acid leaching [9] is carried out directly, huge amounts of equipment investments and chemical reagents will be wasted. Therefore, appropriate incineration pretreatment should be carried out before metal recovery to realize the enrichment of valuable metal elements and sludge reduction [10]. Therefore, it is very important to select an efficient pretreatment method for the comprehensive utilization of NCS.

Microwave heating sometimes exhibits some unique advantages over conventional heating, such as reducing the chemical reaction time and improving product quality [11,12]. Roy [13] described the application of microwave heating to sintering of a wide range of standard powdered metals and found 
that the mechanical properties of the final products were better than that of conventional heating. Furthermore, good results were also obtained when microwave heating was introduced to sludge pretreatment and stabilization. Liao [14] reported that both the volume and weight greatly reduce to $11.4 \%$ when the electroplating sludge was roasted at $600{ }^{\circ} \mathrm{C}$ for $10 \mathrm{~min}$; in the subsequent sulfuric acid leaching process, the leaching rate of nickel and copper can reach more than $97 \%$. Microwave heating technology is also used for the stabilization of heavy metal elements in sludge. Microwave can energize, mitigate, and assist the chemical binding of dipolar molecules and metal ions within a solid structure. With respect to the stabilization process, Menéndez et al. [15] confirmed that the leaching concentration of heavy metals from sludge after microwave treatment is lower than that obtained using traditional electric furnace heating treatment technologies. Chen [16], Hsies [17], and Chan [18] added strong wave-absorbing materials, such as iron, aluminum, and alumina powders, to the sludge to increase the microwave heating efficiency. They found that the leaching concentration of copper ions decreases significantly.

However, all above-mentioned studies lack the key parameters of microwave heating, that is, the high-temperature dielectric characteristics of materials. In general, the dielectric properties of materials are used to evaluate the microwave absorption capability of materials $[19,20]$. The dielectric properties of materials, especially at high temperature, are receiving increased attention. On the measurement of the high-temperature dielectric properties, as early as 1984 Araneta [21] had developed a technique to uncover the high-temperature microwave characterization of dielectric rods using a single microwave source. In addition, there are actually a lot reports about the cavity perturbation method was used to measure the complex permittivity. Lin [22] investigated the dielectric properties of spent adsorbent with zinc sulfate using the cavity perturbation technique at $2.45 \mathrm{GHz}$ from $20^{\circ} \mathrm{C}$ to $1000{ }^{\circ} \mathrm{C}$ and found that $\varepsilon^{\prime}$ and $\varepsilon^{\prime \prime}$ of the sample significantly change with increasing temperature. Jiang [23] reported that the dielectric constants of the molybdenite concentrate increase as the temperature increases in the entire experimental range. Catalá-Civera [24] developed a dual-mode cylindrical cavity with a cross-coupling filter between two different microwave sources to heat and measure the dielectric properties of materials in situ and real-time over a wide temperature range. Furthermore, Li [25] described a broadband from 7 to $18 \mathrm{GHz}$ and a high temperature range from room temperature to 1500 ${ }^{\circ} \mathrm{C}$ dielectric properties test system for low-loss materials using circular cavity method. Also the team of Dr. Kama Huang from the College of Electronics and Information Engineering, Sichuan University, studied the technology used for the measurement of dielectric properties in detail. Based on their study, the polarization characteristics of the chemical reaction system under the action of electromagnetic waves were deduced [26-29].

In the present study, the dielectric properties of NCS were explored at different temperatures and a frequency of $2.45 \mathrm{GHz}$. Both the loss tangent $(\tan \delta)$ and penetration depth $(D p)$ were calculated using the measured dielectric constant $\left(\varepsilon^{\prime}\right)$ and the dielectric loss factor $\left(\varepsilon^{\prime \prime}\right)$. In addition, the heating curves of NCS with power of $1000 \mathrm{~W}$ at different moisture content (dried, $4 \%$, and $8 \%$, dry basis) were studied. Finally, the changes of the microstructure and phase were analyzed by SEM (SPM-S3400N, Hitachi, Tokyo, Japan) and X-ray powder diffraction (XRD) (XRD-7000S/L, Shimadzu, Kyoto, Japan). These data may be useful for comprehensive sludge utilization regeneration, database perfection of dielectric properties, and understanding the microwave mechanism of heating.

\section{Materials and Methods}

\subsection{Raw Materials}

Raw NCS was obtained from a battery manufacturer in the Henan Province, China. The material provided for extracting nickel was dried through preliminary pressure filtration and exposed to the sun for a long time with a moisture content of about $4 \%$.

After being dried in a constant temperature drying oven for $48 \mathrm{~h}$, the samples were analyzed chemically and by XRD. The chemical composition and XRD pattern are shown in Table 1 and Figure 1. 
Table 1. Chemical composition of the nickel-containing sludge (NCS) residue.

\begin{tabular}{ccccccccc}
\hline Composition & $\mathbf{O}$ & $\mathbf{C a}$ & $\mathbf{M g}$ & $\mathbf{C}$ & $\mathbf{N i}$ & $\mathbf{F e}$ & $\mathrm{Si}$ & $\mathbf{C d}$ \\
\hline Content $(\%)$ & 53.42 & 14.09 & 8.67 & 8.30 & 8.02 & 4.64 & 1.57 & 0.71 \\
\hline
\end{tabular}

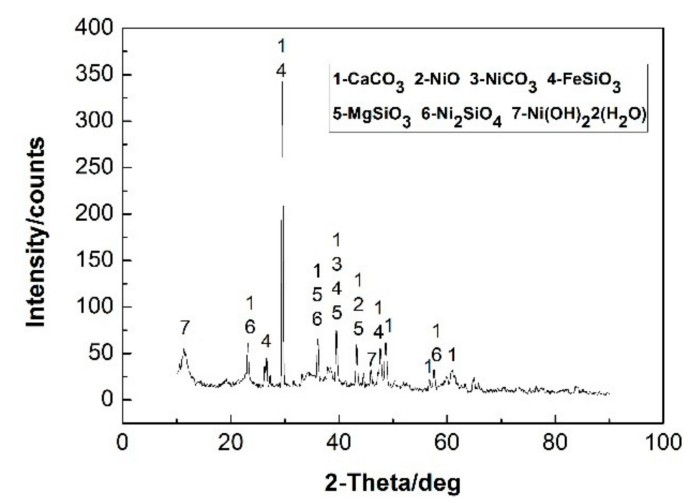

Figure 1. XRD pattern of the raw material.

Table 1 shows that the content of metallic elements in the NCS and nickel content is found to be above $8 \%$. In addition, about $2 \%$ used oil, along with the cleaning wastewater, was found in the raw materials by gravimetric method.

Figure 1 shows that the material composition is relatively complex; the main phase is $\mathrm{CaCO}_{3}$. Magnesium mainly exists in form of $\mathrm{MgSiO}_{3}$, while $\mathrm{Ni}$ mainly exists in form of $\mathrm{NiO}$. Low amounts of $\mathrm{NiCO}_{3}$ and $\mathrm{Ni}(\mathrm{OH})_{2} \cdot 2\left(\mathrm{H}_{2} \mathrm{O}\right)$ are also present, whereas Fe mainly exists as $\mathrm{FeSiO}_{3}$.

\subsection{Experimental Devices}

\subsubsection{Permittivity Measurement System}

The cavity perturbation method has the advantages of accurate measurement and simple operation in the measurement of high temperature dielectric properties of solid materials which was used to measure the dielectric parameters of the NCS at different moisture contents and temperatures [30]. The testing equipment, which has been widely used for the measurement of the dielectric properties of materials was developed by Key Laboratory of Unconventional Metallurgy, Ministry of Education in Kunming University of Science and Technology [22,23]. A schematic of the system is shown in Figure 2.

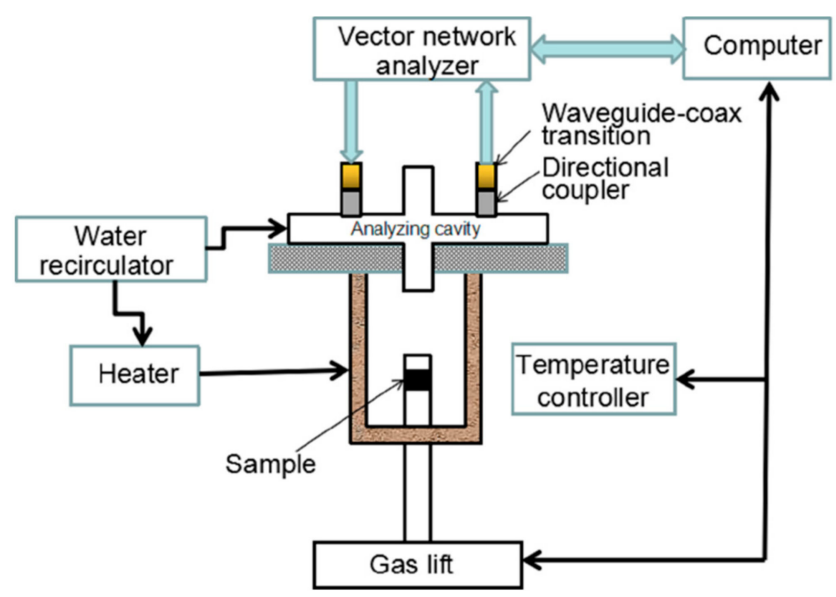

Figure 2. Schematics of the permittivity measurement system.

The device consists of a vector network analyzer (E5071C, Agilent, Santa Clara, CA, USA), waveguide-coax transition, directional coupler, electromagnetic induction heater, water recirculator, 
gas lift, and cylindrical cavity resonator with the inner dimensions of $190 \mathrm{~mm}$ height and $200 \mathrm{~mm}$ diameter $\left(\mathrm{TM}_{0 \mathrm{n} 0}\right)$. The test control unit is connected to a computer via a USB data cable and software calculates the dielectric parameters. The system accuracy was estimated to be $3 \%$ in the dielectric constant and $10 \%$ in the loss factor during the tests, deionized water (the dielectric constant is $78 \mathrm{~F} / \mathrm{m}$ ) and the known data of molybdenite concentrate (the dielectric constant and loss factor are $5.47 \mathrm{~F} / \mathrm{m}$ and 0.478 at $300{ }^{\circ} \mathrm{C}$ ) reported by Jiang [23] were used as standards, resulting in $76.77 \mathrm{~F} / \mathrm{m}, 5.34 \mathrm{~F} / \mathrm{m}$ and 0.442 , respectively, $1.58 \%, 2.37 \%$, and $7.53 \%$ differences.

During the experiments, the test samples were placed into the heater of the permittivity measurement system with a small quartz tube (inner dimensions $4.0 \mathrm{~mm}$, height $52 \mathrm{~mm}$ ). When the NCS was heated to a preset temperature and subsequently lifted into the cavity resonator via the gas lift, the computer rapidly calculated the dielectric parameters using the test-cavity perturbation theory. After the test, the quartz tube was lowered into the heater and heated to a higher preset temperature to measure the permittivity at different temperatures. Each sample was measured three times and its average value was finally taken. In addition, the error of the three times measured value should be within $10 \%$, if the deviation was too large, and took the fourth time.

\subsubsection{Microwave Oven for the Pretreatment Experiments}

A microwave reactor which developed by Key Laboratory of Unconventional Metallurgy, Ministry of Education in Kunming University of Science and Technology with a power of $3 \mathrm{~kW}$ and a frequency of $2.450 \mathrm{GHz}$ was used for the heating experiments. Its schematic is presented in Figure 3. The microwave heating system consists of a temperature control unit with a thermo-element, two magnetrons, a multimode cavity, a quartz glass container with a glass fiber wool, and a data acquisition computer. The thermocouple pyrometer with metallic shield layer was inserted into the center of the sample to measure the heating temperature. It is found that the error of the system is about $\pm 3^{\circ} \mathrm{C}$ (the temperature measured by the system after a period of microwave heating is $386^{\circ} \mathrm{C}$ ) by comparing the data obtained from infrared temperature measurement (after a period of microwave heating, the surface temperature of the material displayed by the infrared thermometer is $383^{\circ} \mathrm{C}$ ) and the data measured after the microwave source shutdown (the temperature measured by the system after the microwave shutdown for $5 \mathrm{~s}$ is $384^{\circ} \mathrm{C}$ ).



Figure 3. Schematic of the microwave roasting system.

During the microwave heating experiments, a certain amount (100 g) sample play as a $15 \mathrm{~mm}$ thin layer loaded into a quartz glass container was placed inside the microwave oven and heated at a certain microwave power $(1000 \mathrm{~W})$ to different temperature. 


\subsection{Data Analysis and Mathematical Modeling}

Complex permittivity is the fundamental property that determines the microwave absorption of a sample. The complex permittivity $\left(\varepsilon^{*}\right)$ can be expressed as:

$$
\varepsilon^{*}=\varepsilon^{\prime}-j \varepsilon^{\prime \prime}
$$

where the real part $\left(\varepsilon^{\prime}\right)$ is often referred to as the dielectric constant, which reflects the ability of the material to store electromagnetic energy within its structure; the imaginary part $\left(\varepsilon^{\prime \prime}\right)$ is the dielectric loss factor that characterizes the ability of the material to convert the stored electromagnetic energy into thermal energy. Another important parameter is the loss tangent $(\tan \delta)$, which describes how well the material dissipates stored energy into heat at a given frequency and temperature. The loss tangent $(\tan \delta)$ can be expressed as:

$$
\tan \delta=\frac{\varepsilon^{\prime \prime}}{\varepsilon^{\prime}}
$$

The power penetration depth $(D p)$ is defined as the depth at which the power of an applied microwave field is reduced to $1 / \mathrm{e}$ of its surface value and is expressed with the following equation:

$$
D_{p}=\frac{\lambda_{0}}{2 \sqrt{2} \pi \sqrt{\varepsilon^{\prime}\left[\sqrt{1+\left(\frac{\varepsilon^{\prime \prime}}{\varepsilon^{\prime}}\right)^{2}}-1\right]}}
$$

where $\lambda_{0}$ is the wavelength $\left(\lambda_{0}=12.24 \mathrm{~cm}\right.$ at $\left.2.45 \mathrm{GHz}\right)$ and $\pi$ is a constant. The penetration depth $(D p)$ of NCS can be calculated using Equation (3) and the measured data.

\section{Results and Discussion}

\subsection{TG-DSC of the NCS}

Figure 4 shows the thermal behavior of NCS concentrate $(16.5835 \mathrm{mg})$ which was examined by the thermol-analytical instrument, NETZSCH SAT 449F5 (NETZSCH, Selb, Germany) under $\mathrm{N}_{2}$ atmosphere at a $10^{\circ} \mathrm{C} / \mathrm{min}$ heating rate. It is evident that the weight of the NCS concentrate decreases with increasing temperature. The weight loss in the temperature range from $20^{\circ} \mathrm{C}$ to $200{ }^{\circ} \mathrm{C}$ is $\sim 12.5 \%$ based on the TG curve, while two endothermic peaks are observed in the DSC curve between $20^{\circ} \mathrm{C}$ and $200{ }^{\circ} \mathrm{C}$, corresponding to organics and water volatilization, respectively. Above $200^{\circ} \mathrm{C}$, the DSC curve continues to decrease and notable endothermic and exothermic peaks are not observed. The weight loss is $\sim 13 \%$ from $200{ }^{\circ} \mathrm{C}$ to $600{ }^{\circ} \mathrm{C}$ based on the TG curve. During this process, $\mathrm{NiCO}_{3}$ and $\mathrm{Ni}(\mathrm{OH})_{2}$ will decompose to $\mathrm{NiO}[31,32]$.

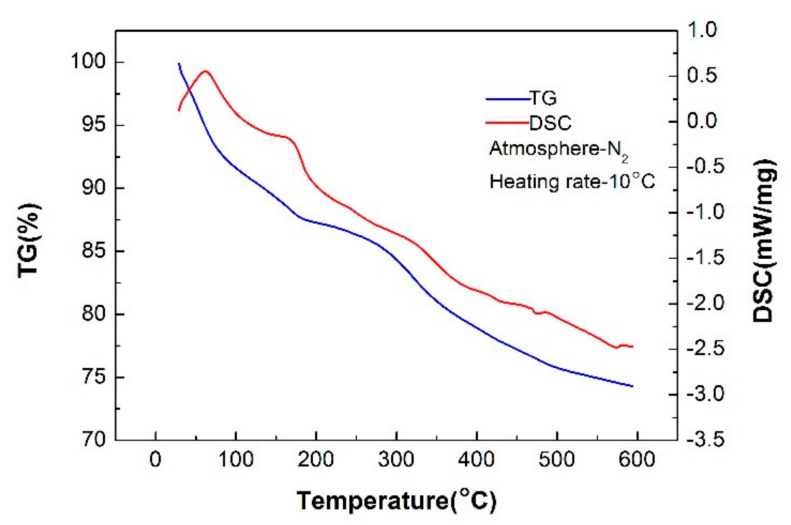

Figure 4. Thermogravimetric analysis (TG) and differential scanning calorimetry (DSC) curves of NCS. 


\subsection{Dielectric Properties of the NCS}

The effect of the temperature on the dielectric properties of NCS at a frequency of $2.45 \mathrm{GHz}$ is shown in Figure 5. Figure 5a shows that the dielectric constant of NCS gradually increases with increasing temperature from room temperature to $600^{\circ} \mathrm{C}$ which is attributed to the formation of nickel oxide which relative to chemical reactions in the NCS, as will be stated in Figure 4. The NiO, same as $\mathrm{Fe}_{2} \mathrm{O}_{3}, \mathrm{CuO}$, and $\mathrm{MnO}_{2}$, can be quickly heated by microwave [33]. The dielectric constant gradually increases from 2.8 to 4.1 in this temperature range. The same tendency of the dielectric constant of the NCS to increase with increasing temperature is also observed in other ores and minerals [34]. Compared with kaolin ores [34] and natural ilmenite [35], the NCS exhibits a lower dielectric constant.

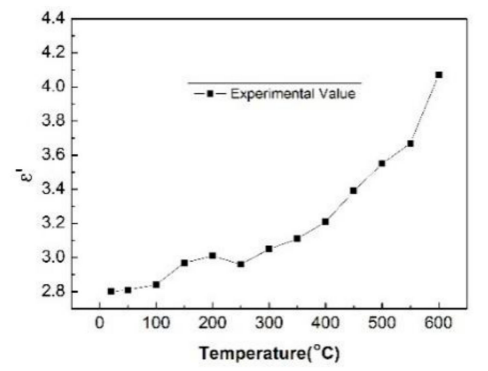

(a)

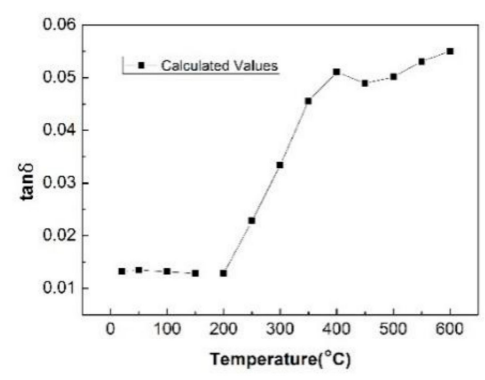

(c)



(b)



(d)

Figure 5. Relative dielectric properties of the dried NCS at different temperatures. (a) Relative dielectric constant $\left(\varepsilon^{\prime}\right),(\mathbf{b})$ relative loss factor $\left(\varepsilon^{\prime \prime}\right),(\mathbf{c})$ dielectric loss angle tangent $(\tan \delta)$, and (d) power penetration depth.

Figure $5 \mathrm{~b}$ shows that the variation of the dielectric loss factor $\left(\varepsilon^{\prime \prime}\right)$ of NCS with the temperature is the same as that of the dielectric constant $\left(\varepsilon^{\prime}\right)$. The loss factor slightly increases from 0.037 to 0.224 in this temperature range. However, a small change is observed in the curve of the dielectric loss factor at $300{ }^{\circ} \mathrm{C}$ because of the release of volatile matter and the phase transformation in this temperature range, which is confirmed by Figure 4.

Figure $5 \mathrm{c}$ shows the temperature dependence of the dielectric loss tangent at $2.45 \mathrm{GHz}$. Based on the statement of Laybourn [36], the NCS is a medium-loss material because its tan $\delta$ value ranges from 0.003-0.03 when the temperature is below $300{ }^{\circ} \mathrm{C}$. It then transforms into a high-loss material at $\tan \delta$ values above 0.03 when the temperature changes from $300{ }^{\circ} \mathrm{C}$ to $600{ }^{\circ} \mathrm{C}$. At temperatures below $200{ }^{\circ} \mathrm{C}$, the loss tangent reaches a stable level of 0.013 and then rapidly increases when the temperature is greater than $300^{\circ} \mathrm{C}$; the value of the loss tangent almost doubles compared with its average value in the range of $20^{\circ} \mathrm{C}-600{ }^{\circ} \mathrm{C}$, reaching a maximum value of 0.055 .

Figure $5 \mathrm{~d}$ presents the temperature dependence of the penetration depth at $2.45 \mathrm{GHz}$. Thee variation of $D P$ is inverse to that of the dielectric loss tangent. The optimum thickness for uniform heat varies from 86 to $17 \mathrm{~cm}$ from room temperature to $600{ }^{\circ} \mathrm{C}$. Based on the microwave roasting test for NCS, the material thickness has no effect on the uniformity of microwave heating. 
Based on the analysis in Figure 5, the NCS is a medium-loss material at low temperature; its microwave heating efficiency is low, which agrees with literature data [15]. Chen [16], Hsies [17], and Chan [18] added strong wave-absorbing materials, such as iron, aluminum, and alumina powders, to the sludge to increase the microwave heating efficiency. However, the analysis of the dielectric properties of NCS with different moisture contents, which are shown in Figure 5, shows that the dielectric properties of NCS significantly increase with the moisture content. When the moisture content of the materials is $\sim 4 \%$, the value of the loss angle tangent $(\tan \delta)$ of the NCS is far higher than that of the temperature. Therefore, the moisture content of the material can be reduced to $\sim 4 \%$ in the drying stage of the material, which provides convenient conditions for subsequent microwave pretreatment. Note that the penetration depth of the microwaves will sharply drop below $4 \mathrm{~cm}$ with increasing moisture content.

\subsection{Microwave Heating Curves of the NCS}

A nonlinear relationship is indicated by the heating rate curves of the NCS at different moisture contents, as shown in Figure 6. Figure 6 shows that the increase can be divided into two parts. The sample temperature slowly increases at a heating rate of $16.2^{\circ} \mathrm{C} / \mathrm{min}$ for dried materials in the temperature range of $20{ }^{\circ} \mathrm{C}-200^{\circ} \mathrm{C}$ and rapidly increases at a heating rate of $42.1^{\circ} \mathrm{C} / \mathrm{min}$ for dried materials in the range of $200{ }^{\circ} \mathrm{C}-400{ }^{\circ} \mathrm{C}$. These results are in good agreement with the dielectric properties of the NCS, as shown in Figure 5. At $20^{\circ} \mathrm{C}-200{ }^{\circ} \mathrm{C}$ and lower $\varepsilon^{\prime}, \varepsilon^{\prime \prime}$, and tan $\delta$ values, only a small fraction of the radiation energy is converted into thermal energy and the material temperature increases slowly. When the temperature is greater than $200{ }^{\circ} \mathrm{C}$, the values of $\varepsilon^{\prime}, \varepsilon^{\prime \prime}$, and $\tan \delta$ swiftly increase and the material temperature rapidly increases in a relatively short time. In addition, the comparison of the heating characteristics of the materials with different moisture contents shows that the material containing a certain amount of water in the initial stage promotes the microwave heating efficiency. At an initial water content of $4 \%$ and $8 \%$, the heating rate of the material is $36.4 \%$ and $11.1 \%$ higher, respectively, than that of the dried materials, which is confirmed by Figure 7 .

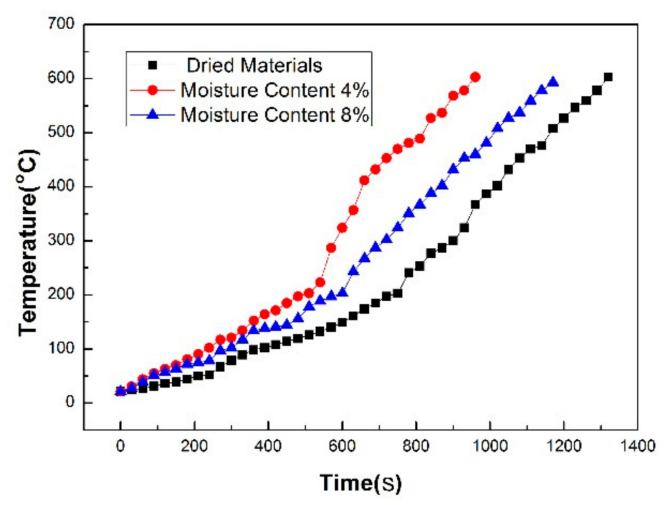

Figure 6. Heating rate curves of NCS with power of $1000 \mathrm{~W}$ at different moisture content.

\subsection{Changes in Physical Properties of the NCS After Pretreatment}

Figure 8 shows that the main phase of the sample is still $\mathrm{CaCO}_{3}$ after microwave or conventional pretreatment, in addition to some silicates. Nickel carbonate and nickel hydroxide disappear (spots 1 and 3) and meanwhile the peak of nickel oxide significantly increases (spots 2 and 4 in Figure 8). Therefore, the main phases change of the materials after pretreatment is the transformation of nickel carbonate and nickel hydroxide to $\mathrm{NiO}$. Compared with conventional heating, it can be found that the microwave heating process has a better treatment effect. 


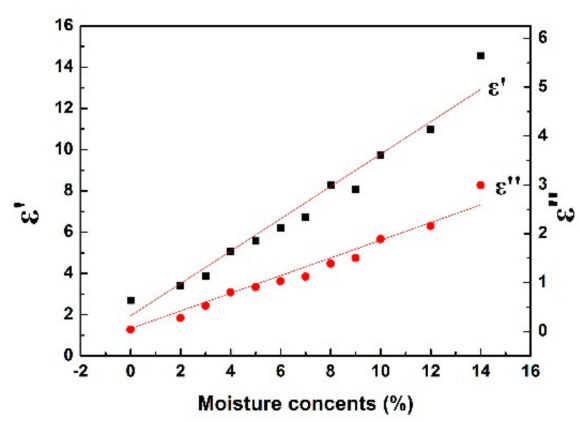

(a)

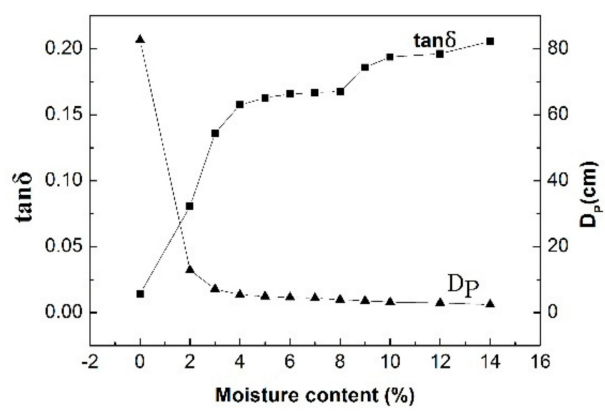

(b)

Figure 7. Relative dielectric properties of the NCS for different moisture contents. (a) Relative dielectric constant $\left(\varepsilon^{\prime}\right)$ and relative loss factor $\left(\varepsilon^{\prime \prime}\right)$ for different moisture contents. (b) dielectric loss angle tangent $(\tan \delta)$ and power penetration depth $(D P)$ for different moisture contents.

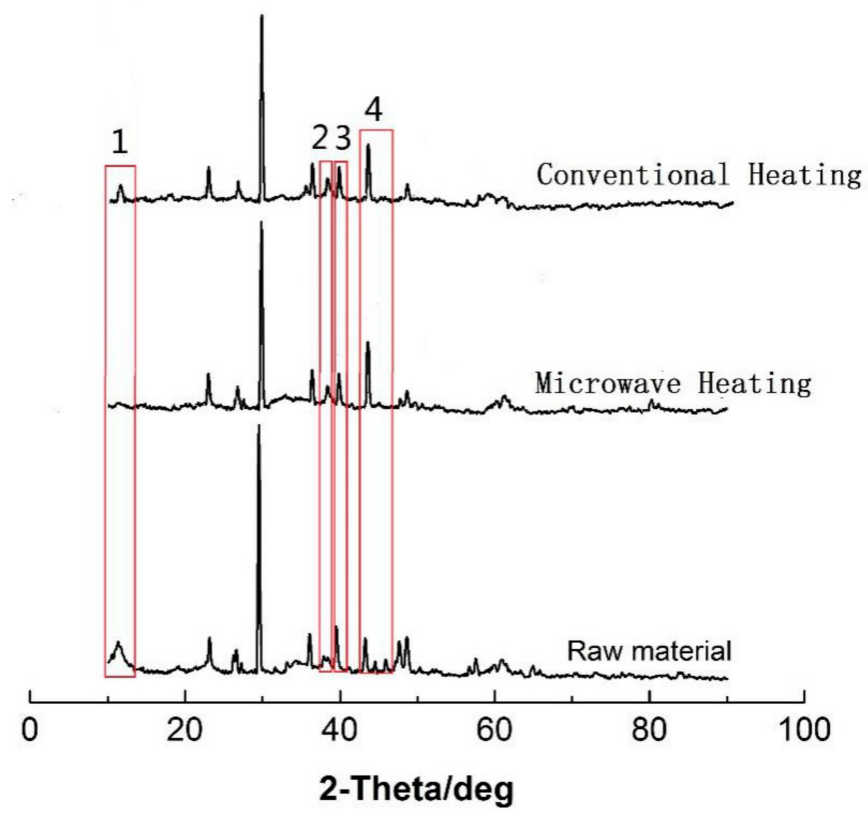

Figure 8. XRD (Shimadzu XRD-7000S/L) patterns of the products roasted at $450{ }^{\circ} \mathrm{C}$ for $10 \mathrm{~min}$ by microwave and conventional heating.

Figure 9 shows the changes in particle size of the roasted products and mass loss at different temperature by microwave and conventional heating. The particle size of the roasted products was examined by the particle size analyzer, Microtrac S3500 (Microtrac, Florida, US). It can be found from Figure 9a that the roasted products by microwave heating have a smaller particle size than that of conventional heating. The main reasons are the different absorption characteristics of each component in the NCS and the non-uniform electric field of the microwave field, which produces a large temperature gradient and makes the material particles crack. This characteristic of microwave is often used in assisting grinding, as Sahoo [37] and Kumar [38] report. In addition, the weight of NCS is reduced by more than $20 \%$ after roasted at $450{ }^{\circ} \mathrm{C}$ for $10 \mathrm{~min}$ in microwave field, shown in Figure $9 \mathrm{~b}$. The weight loss of microwave heating is $10 \%$ higher than that of conventional heating. Therefore, microwave roasting can promote the subsequent leaching process. It is also observed in Figure $9 \mathrm{~b}$ that as the temperature continues to rise, the weight loss of material tends to be stable. 


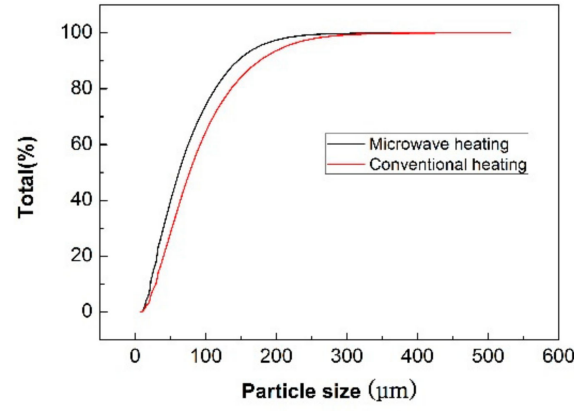

(a)

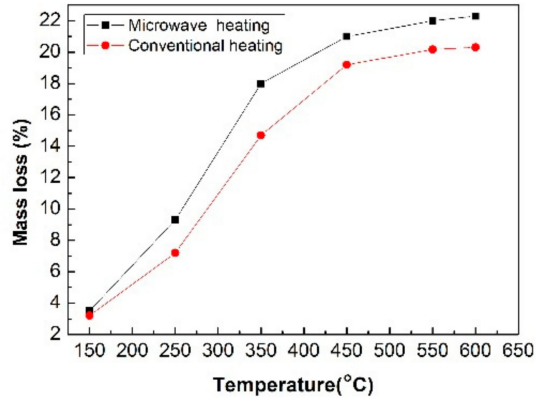

(b)

Figure 9. Changes in basic physical properties. (a) Particle size distribution of the products roasted at $450{ }^{\circ} \mathrm{C}$ for $10 \mathrm{~min}$ by microwave and conventional heating and (b) variation of mass loss after microwave and conventional roasting at different temperature for $10 \mathrm{~min}$.

\subsection{Effect of Microwave Pretreatment on Nickel Leaching Rate}

In order to compare the effect of conventional and microwave pretreatment, acid leaching experiments were carried out at room temperature which is show in Figure 10. The leaching conditions were $0.35 \mathrm{~mL} / \mathrm{g}$ of concentrated sulfuric acid, solid-liquid ratio 1:3 and material particle size of $-100 \mu \mathrm{m}$.

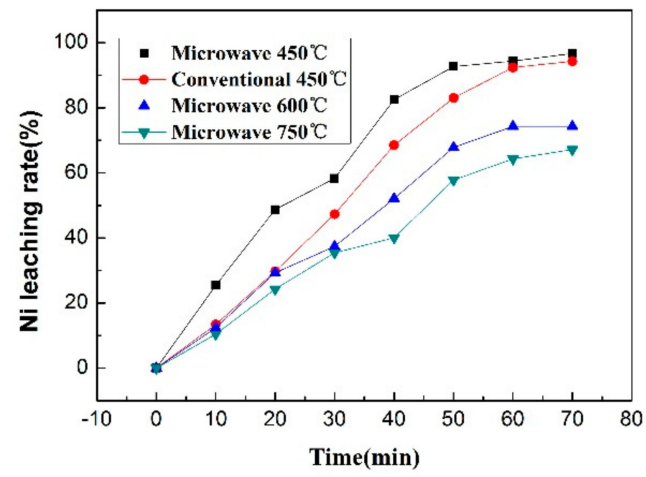

Figure 10. Effect of pretreatment temperature on nickel leaching rate.

Figure 10 shows that the nickel leaching rate can reach above $94 \%$ after conventional and microwave pretreatment at $450^{\circ} \mathrm{C}$. In particular, microwave pretreatment can reduce the leaching time of $20 \mathrm{~min}$ than that of conventional. This is because the microwave roasting can cause more holes and cracks in the NCS which will promote the migration of nickel. But when the pretreatment temperature risen to $750{ }^{\circ} \mathrm{C}$, the leaching rate of nickel fell sharply to only about $60 \%$. The main reason is that a coating will be formed around the nickel with the changes of microstructure or the mixture changes into glassy residue at high temperature which greatly reduce the rate of nickel dissolution $[15,16]$.

\subsection{Intensification Mechanism of the Microwave Heating Process}

The power absorbed by the material is directly proportional to the loss factor, frequency, and intensity of the electric field, as shown in Equation (4):

$$
P_{d}=2 \pi f E_{i}^{2} \varepsilon_{0} \varepsilon^{\prime \prime}
$$

where $\varepsilon_{0}$ is the permittivity of the free space $\left(8.854 \mathrm{pF} \cdot \mathrm{m}^{-1}\right) ; \varepsilon^{\prime \prime}$ is the imaginary part of the complex permittivity, also known as the loss factor $\left(\mathrm{F} \cdot \mathrm{m}^{-1}\right) ; E_{i}$ is the internal electric field $\left(\mathrm{V} \cdot \mathrm{m}^{-1}\right)$; $f$ denotes the frequency $(\mathrm{Hz})$; and $P_{d}$ is the power density dissipated in the heated material $\left(\mathrm{W} \cdot \mathrm{m}^{-3}\right)$.

Based on this equation, microwave heating depends on two main parameters, that is, $E$ and $\varepsilon^{\prime \prime}$.

Therefore, the microwave roasting mechanism mainly contains the following steps: 
Stage 1: At low temperatures, the dielectric loss of a mineral is relatively low and the penetration depth is high. Thus, the energy of the microwaves can be concentrated into an electric peak. Therefore, a state of flash heating and reaction occurs inside the material because of the highly localized electric field, which is indicated by the red area in Figure 11 (Stage 1).

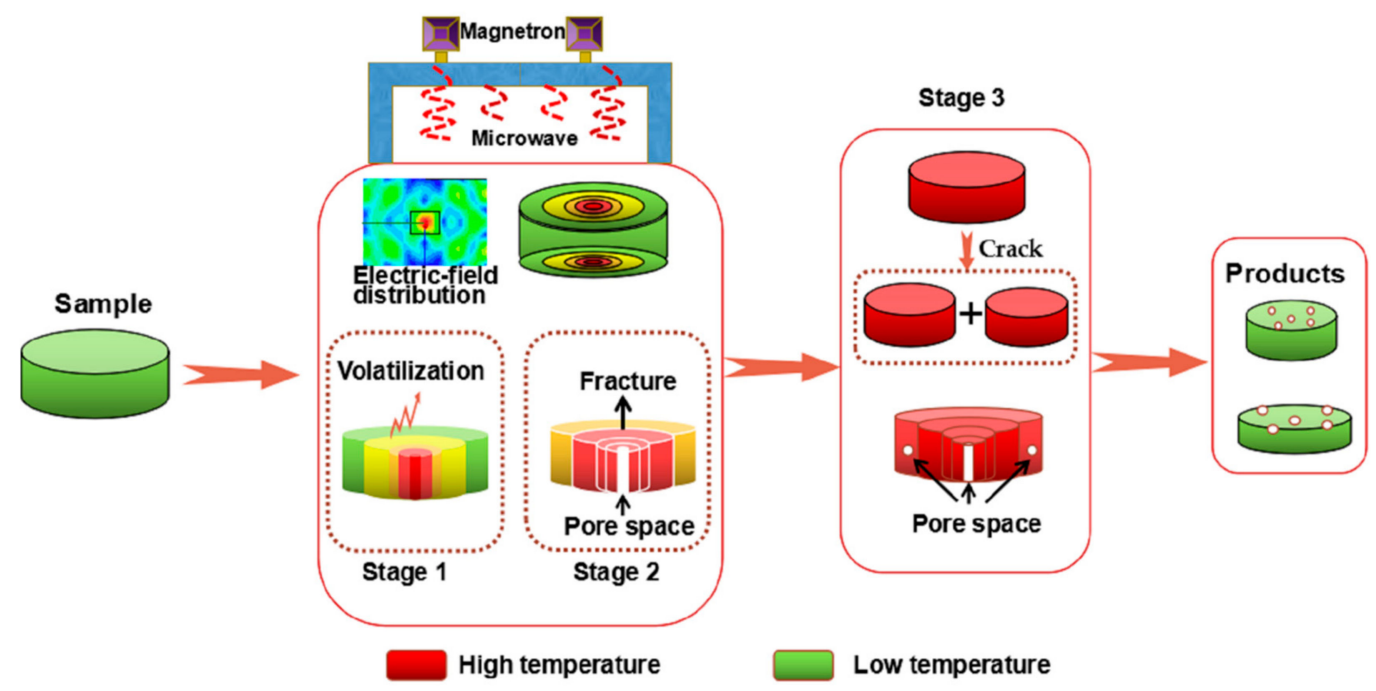

Figure 11. Schematic diagram of the microwave heating process of the NCS.

Stage 2: As the temperature of the hot core area reaches the reaction stage $\left(\sim 200{ }^{\circ} \mathrm{C}\right)$, the NCS particles in the core quickly start the chemical reaction that generates a gaseous product. Many pores with different sizes are created, as shown in Figure 11 (Stage 2) and Figure 12b (the red circle). The uneven particles, loose structure, and large number of pores are conducive to the penetration and multiple reflection of microwaves in the NCS, which improve the microwave heating efficiency, as shown in Figure 6. At the same time, these porous microstructures are favorable for nickel leaching, as shown in Figure 10.

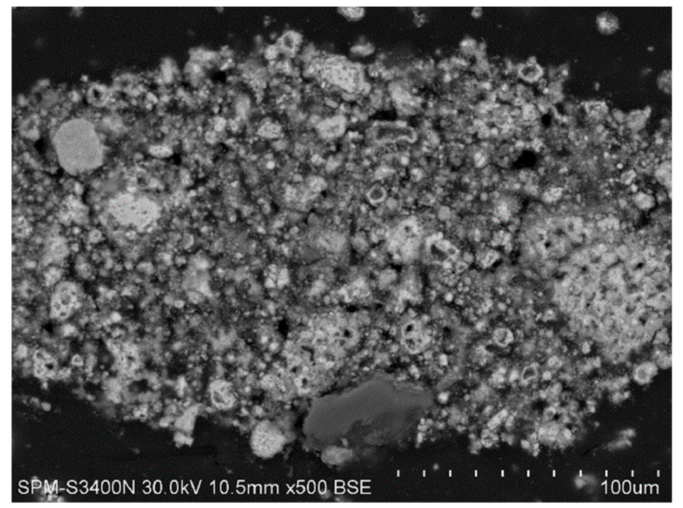

(a)

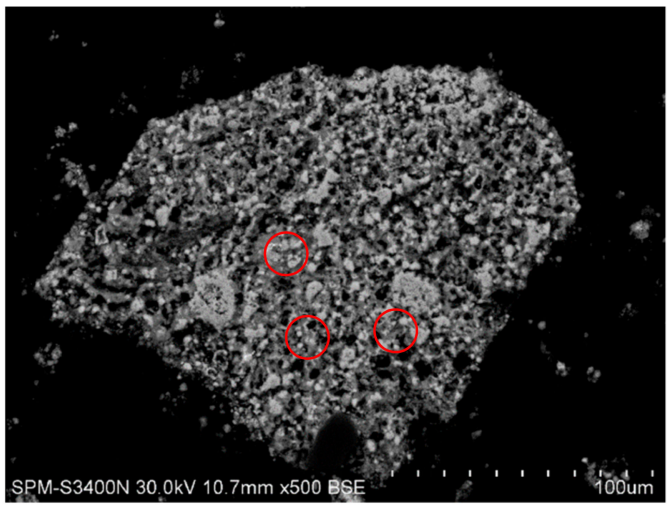

(b)

Figure 12. SEM micrographs of the materials before and after roasting. (a) Raw material and (b) microwave heating products.

Stage 3: The heat in the hot core region is conducted to the nearby area, which can dramatically raise the dielectric loss of the material in the heated region, as shown in Figure 5b,c. Thus, this nearby region will absorb more microwave energy and undergo rapid heating, as indicated by Equation (4). The increase in the dielectric loss will decrease the penetration depth of the microwaves, as shown in Equation (3) and Figure 5d. The energy absorbed by the hot core region decreases; hence, the temperature 
increase rate decreases and the heat is continuously conducted outwards. The layer-by-layer reaction process continues until a uniform temperature and reaction state is reached, as shown in Figure 11 (Stage 3).

\section{Conclusions}

1. The dielectric properties of the NCS were measured at different temperatures and moisture contents using the microwave cavity perturbation method at $2.45 \mathrm{GHz}$. The values of the dielectric constant and relative loss factor of the NCS increase with increasing temperature. The $\tan \delta$ and $D P$ are also determined using Equations (2) and (3). At temperatures below $200{ }^{\circ} \mathrm{C}$, the tan $\delta$ value reaches a stable level of 0.013 and then rapidly increases when the temperature is greater than $300{ }^{\circ} \mathrm{C}$, reaching a maximum value of 0.055 . The optimum thickness for uniform heat varies from 86 to $17 \mathrm{~cm}$ from room temperature to $600^{\circ} \mathrm{C}$. The dielectric properties of NCS significantly increase with the moisture content. When the moisture content of the materials is $\sim 4 \%$, the value of the loss angle tangent $(\tan \delta)$ of the NCS is far higher than that of the temperature.

2. Within $22 \mathrm{~min}$, the dried material temperature reaches more than $600^{\circ} \mathrm{C}$ in a microwave field. The heating curve can be divided into two parts. The sample temperature slowly increases at a heating rate of $16.2{ }^{\circ} \mathrm{C} / \mathrm{min}$ below $200{ }^{\circ} \mathrm{C}$ and rapidly increases at a heating rate of $42.1^{\circ} \mathrm{C} / \mathrm{min}$ from $200^{\circ} \mathrm{C}$ to $600^{\circ} \mathrm{C}$. The comparison of the heating characteristics of the materials with different moisture contents shows that the heating rate of the material is $36.4 \%$ and $11.1 \%$ higher than that of the dried materials when the initial moisture content is $4 \%$ or $8 \%$, respectively.

3. The microwave pretreatment process for the NCS is feasible and the dried sample can be reduced by $21 \%$ without changing the major phases. The weight loss of microwave heating is $10 \%$ higher, the particle size of the roasted products is smaller and while the weight of NCS is reduced by more than $20 \%$, the particle size is significantly reduced and the leaching time reduce $20 \mathrm{~min}$ than that of conventional heating. The microwave roasting mechanism was evaluated using modern analysis methods such as chemical analysis, XRD, and SEM.

Author Contributions: F.L. and G.S. conceived and designed the experiments; Z.G. performed the experiments; Z.G. and F.L. developed the model, analyzed the data, and wrote the initial draft of the manuscript; D.Z. and F.C. assisted the experiment procedures; P.G. reviewed and contributed to the final manuscript.

Funding: This work was funded by Foundation of Henan Educational Committee (Grant No. 18A530002) and Key Scientific and Technological Project of Henan Province (Grant No. 182102310896).

Conflicts of Interest: The authors declare no conflict of interest.

\section{References}

1. Yan, X.; Li, Q.; Chai, L.; Wang, Q. Formation of abiological granular sludge-A facile and bioinspired proposal for improving sludge settling performance during heavy metal wastewater treatment. Chemosphere 2014, 113, 36-41. [CrossRef] [PubMed]

2. Hsieh, C.H.; Shih, K.; Hu, C.Y.; Lo, S.L.; Li, N.H.; Cheng, Y.T. The effects of salinity and temperature on phase transformation of copper-laden sludge. J. Hazard. Mater. 2013, 244-245, 501-506. [CrossRef] [PubMed]

3. Zhang, P.; Ma, Y.; Xie, F. Impacts of ultrasound on selective leaching recovery of heavy metals from metal-containing waste sludge. J. Mater. Cycles Waste 2013, 15, 530-538. [CrossRef]

4. Silva, J.E.; Paiva, A.P.; Soares, D.; Labrincha, A.; Castro, F. Solvent extraction applied to the recovery of heavy metals from galvanic sludge. J. Hazard. Mater. 2005, 120, 113-118. [CrossRef] [PubMed]

5. $\quad$ Liang, Y.J.; Chai, L.Y.; Min, X.B.; Tang, C.J.; Zhang, H.J.; Ke, Y.; Xie, X.D. Hydrothermal sulfidation and floatation treatment of heavy-metal-containing sludge for recovery and stabilization. J. Hazard. Mater. 2012, 217-218, 307-314. [CrossRef] [PubMed]

6. Shih, K.; White, T.; Leckie, J.O. Nickel stabilization efficiency of aluminate and ferrite spinels and their leaching behavior. Environ. Sci. Technol. 2006, 40, 5520-5526. [CrossRef] [PubMed]

7. Li, C.T.; Lee, W.J.; Huang, K.L.; Fu, S.F.; Lait, Y.C. Vitrification of chromium electroplating sludge. Environ. Sci. Technol. 2007, 41, 2950-2956. [CrossRef] 
8. Yi, Z.; Wang, Z.K.; Xia, X.; Chen, Y.Q.; Qi, T. Recovery of heavy metals from electroplating sludge and stainless steel pickle waste liquid by ammonia leaching method. J. Environ. Sci. China 1999, 11, 381-384.

9. Silva, J.E.; Soares, D.; Paiva, A.P.; Labrincha, J.A.; Castro, F. Leaching behaviour of a galvanic sludge in sulphuric acid and ammoniacal media. J. Hazard. Mater. 2005, 121, 195-202. [CrossRef]

10. Dang, X.E.; Lan, X.Z.; Dong, Y. Study on Recovering of Value Metals from Acid Leaching Solution of Roasted Electroplating Sludge. Adv. Mater. Res. 2012, 524-527, 1951-1955. [CrossRef]

11. Jones, D.A.; Lelyveld, T.P.; Mavrofidis, S.D.; Kingman, S.W.; Miles, N.J. Microwave heating applications in environmental engineering-A review. Resour. Conserv. Recycl. 2002, 34, 75-90. [CrossRef]

12. Kingman, S.W.; Rowson, N.A. Microwave treatment of minerals-a review. Miner. Eng. 1998, 11, $1081-1087$. [CrossRef]

13. Roy, R.; Agrawal, D.; Cheng, J.; Gedevanishvili, S. Full sintering of powdered-metal bodies in a microwave field. Nature 1999, 399, 304-304. [CrossRef]

14. Liao, C.; Sun, S.; Chen, Q. Study on metal recovery and innoxious diposal of eleetroplating sludge using ineineration. Shanghai Environ. Sci. 2002, 21, 491-500. (In Chinese)

15. Menéndez, J.A.; Domínguez, A.; Inguanzo, M.; Pis, J.J. Microwave-induced drying, pyrolysis and gasification (MWDPG) of sewage sludge: Vitrification of the solid residue. J. Anal. Appl. Pyrolysis 2005, 74, 406-412. [CrossRef]

16. Chen, C.L.; Lo, S.L.; Kuan, W.H.; Hsieh, C.H. Stabilization of Cu in acid-extracted industrial sludge using a microwave process. J. Hazard. Mater. 2005, 123, 256-261. [CrossRef] [PubMed]

17. Hsieh, C.H.; Lo, S.L.; Chiueh, P.T.; Kuan, W.H.; Chen, C.L. Microwave enhanced stabilization of heavy metal sludge. J. Hazard. Mater. 2007, 139, 160-166. [CrossRef] [PubMed]

18. Chan, W.; Wong, W.; Liao, P.; Lo, K. Sewage sludge nutrient solubilization using a single-stage microwave treatment. Environ. Lett. 2007, 42, 59-63. [CrossRef] [PubMed]

19. Dawson, E.A.; Parkes, G.M.B.; Barnes, P.A.; Bond, G.; Mao, R. The generation of microwave-induced plasma in granular active carbons under fluidised bed conditions. Carbon 2008, 46, 220-228. [CrossRef]

20. Zlotorzynski, A. The application of microwave radiation to analytical and environmental chemistry. Crit. Rev. Anal. Chem. 1995, 25, 43-76. [CrossRef]

21. Araneta, J.C.; Brodwin, M.E.; Kriegsmann, G.A. High-temperature microwave characterization of dielectric rods. IEEE Trans. Microw. Theory 1984, 32, 1328-1335. [CrossRef]

22. Lin, G.; Liu, C.; Zhang, L.; Hu, T.; Peng, J.; Li, J.; Wang, X. High temperature dielectric properties of spent adsorbent with zinc sulfate by cavity perturbation technique. J. Hazard. Mater. 2017, 330, 36-45. [CrossRef] [PubMed]

23. Jiang, Y.; Liu, B.; Liu, P.; Peng, J.; Zhang, L. Dielectric properties and oxidation roasting of molybdenite concentrate by using microwave energy at $2.45 \mathrm{GHz}$ frequency. Metall. Mater. Trans. B 2017, 48, 3047-3057.

24. Catalá-Civera, J.M.; Canós, A.J.; Plaza-González, P.; Gutiérrez, J.D.; García-Baños, B.; Peñaranda-Foix, F.L. Dynamic Measurement of Dielectric Properties of Materials at High Temperature During Microwave Heating in a Dual Mode Cylindrical Cavity. IEEE Trans. Microw. Theory 2015, 63, 2905-2914. [CrossRef]

25. Li, E.; Nie, Z.P.; Guo, G.; Zhang, Q.; Li, Z.; He, F. Broadband measurements of dielectric properties of low-loss materials at high temperatures using circular cavity method. Prog. Electromagn. Res. 2009, 92, 103-120. [CrossRef]

26. Huang, K.M.; Cao, X.J.; Liu, C.; Liu, C.J.; Xu, X.B. Measurement/computation of effective permittivity of dilute solution in saponification reaction. IEEE Trans. Microw. Theory 2003, 51, 2106-2111. [CrossRef]

27. Sun, H.R.; Huang, K.M. A novel microwave cancellation circuit for measuring nonlinear dielectric changes of polar solution under microwave fields. J. Phys. D Appl. Phys. 2015, 48, 475-502. [CrossRef]

28. Huang, K.; Zhu, H.; Wu, L. Temperature cycle measurement for effective permittivity of biodiesel reaction. Bioresour. Technol. 2013, 131, 541-544. [CrossRef]

29. Yang, X.; Huang, K. Study on the key problems of interaction between microwave and chemical reaction. Front. Electr. Electr. Eng. China SPCU 2007, 2, 473-480. [CrossRef]

30. Sheen, J. Study of microwave dielectric properties measurements by various resonance techniques. Measurement 2005, 37, 123-130. [CrossRef]

31. Henmi, H.; Mori, M.; Hirayama, T.; Mizutani, N.; Kato, M. Influence of the self-generated and controlled atmosphere on the thermal decomposition of basic nickel carbonate, $\mathrm{NiCO}_{3} \cdot 2 \mathrm{Ni}(\mathrm{OH})_{2} \cdot 4 \mathrm{H}_{2} \mathrm{O}$. Thermochim. Acta 1986, 104, 101-109. [CrossRef] 
32. Cronan, C.L.; Micale, F.J.; Topić, M.; Leidheiser, H., Jr.; Zettlemoyer, A.C. Surface properties of $\mathrm{Ni}(\mathrm{OH})_{2}$, and $\mathrm{NiO}$. II. Mechanism for the thermal decomposition of $\mathrm{Ni}(\mathrm{OH})_{2}$, and other metal hydroxides. J. Colloid Interface Sci. 2012, 55, 546-557. [CrossRef]

33. Haque, K.E. Microwave energy for mineral treatment processes-A brief review. Int. J. Miner. Process. 1999, 57, 1-24. [CrossRef]

34. Pickles, C.A. Microwave heating behaviour of nickeliferous limonitic laterite ores. Miner. Eng. 2004, 17, 775-784. [CrossRef]

35. Chiteme, C.; Mulaba-Bafubiandi, A.F. An investigation on electrical properties of microwave treated natural ilmenite $\left(\mathrm{FeTiO}_{3}\right)$. J. Mater. Sci. 2006, 41, 2365-2372. [CrossRef]

36. Laybourn, A.; Katrib, J.; Palade, P.A.; Easun, T.L.; Champness, N.R.; Schroder, M.; Kingman, S.W. Understanding the electromagnetic interaction of metal organic framework reactants in aqueous solution at microwave frequencies. Phys. Chem. Chem. Phys. 2016, 18, 5419-5431. [CrossRef] [PubMed]

37. Sahoo, B.K.; De, S.; Meikap, B.C. Improvement of grinding characteristics of Indian coal by microwave pre-treatment. Fuel Process. Technol. 2011, 92, 1920-1928. [CrossRef]

38. Kumar, P.; Sahoo, B.K.; De, S.; Kar, D.D.; Chakraborty, S.; Meikap, B.C. Iron ore grindability improvement by microwave pre-treatment. J. Ind. Eng. Chem. 2010, 16, 805-812. [CrossRef]

(C) 2019 by the authors. Licensee MDPI, Basel, Switzerland. This article is an open access article distributed under the terms and conditions of the Creative Commons Attribution (CC BY) license (http://creativecommons.org/licenses/by/4.0/). 